for going his round, and very frequently, owing to some cause or other, it is considerably past that hour before he makes bis appearance, and as the demonstration com. mences at nine o'clock, it is evident that the time is very limited for the pupil to make his observations on the numerous and interesting cases that are in the wards.

Perhaps, Mr. Editor, you or some of your numerous readers will be kind enough to inform me what reason is assigned for Dr. Latham's paying his visit at so early an hour; for I am contident the majority of his pupils would prefer his coming in the middle of the day, in the manner of the other physicians and surgeons. I am, sir, your obedient servant,

A Medicar Pupil.

November, 1829.

CONFINEMENT OF SUPPOSED LUNATICS.

To R. Browne, Esq. one of the Metropolitan Commisstoners of Lunacy, \&c.

$S_{I R},-$ In your letter to the editor of $T h e$ Times of the 11th instant, you state that the law relative to the insane is as follows:"That no person or persons represented or alleged to be insane, shall be put under any restraint by any individual (not a relutive, $o v a$ committee), without a witten order from an authorised person, and the previous personal and separate examination of ' $t w o$ ' medical practitioners of the state of mind of the patient."

I beg most respectfully to ask, if by the above law, a relative can put a person un. der restraint who is supposed to be insane, without the previous and separate examination of two medical practitioners, or without any examination by competeut persons, of the state of mind of the patient?

If it be so, I conceive an individual, even in the present reformed state of the law, might be confined in the house of a malig. nant and rapacious relative, although in a perfectly sound state of mind.

I also beg leave to ask, to what extent the present act would affect a medical practi. tioner, in the event of his giving a false certificate, or one without previous examination of the patient. I should consider the heinousness of such an offence to be so great, that nothing short of transportation for life, or hanging, would be commensurate to the crime. The farour of an answer through the medium of TuE LAscer, would oblige, Sir, your obedient servant,

An INQuirer.

\section{ON THE PULMONARY CREPITOUS RATTLE.}

By JoHN WHITE, Esq., M.R.C.S. St. Neots.

As important advantage attending the publication of The LANCET is, that by its means, new opinions may be made known to every member of the medical profession. If the opinions be erroneous, they may be confuted by the very same means to which their publicity is owing. This latter circumstance will render unnecessary any apo. logy from me, for disputing the correctness of the explanation of the crepitous rattle which is given by Laennec.

The description of the crepitous rattle cannot be given better than in the words of its illustrious disccverer, as translated by Dr. Forbes. I will ard, too, his explana. tion of the cause :- "The moist crepitous rattle has evidently its site in the substance of the lungs. It resembles the sound pro. duced by the crepitation of salt 3 in a vessel exposed to a gentle heat, or that produced by blowing into a dried bladder, or it is still more like that emitted by the beally lungs, when distended by air and compressed in the hand, only stronger. Besides the sound of crepitation, a sensation of humidity in the part is clearly conveyed. We feel that the pulmonary cells contain a watery fluid as well as air, and that the intermix. ture of the two fluids produces bubbles of extreme minuteness." Of this supposed presence of the two fluids, I doubt the cor. rectness; and even il they were prored to be present in the pulmonary cells, I do not think their intermixture in such very minute quantities as must necessarily be contained in each cell, would produce the sound known as the crepitous rattle.

The crepitous rattle is invariably present in the first stage of pneumonia, and is supposed to indicate inflammation of the air. cells, atterded with a secretion of a watery fluid. In every inflarnmation of a mucous membrane which comes under the cognizance of the senses, it is evident, that in the first stage of the inflammation, as suppression of the natural secretion occurs, and a consequent preternatural degree of dryness of the inflamed membrane. In proof of this circumstance, I need hardly mention the sensation of dryness and grittiness which is experienced in inflammation of the conjunc. tiva, or the still more common occurrence of the dryness felt in the commencement of a coryga or catarrh. But although these effects of inflammation of a mucous mem. brane are so constantly presented to our ob. servation, it is supposed that the air-cells, whose lining membrane is mucous, no soone: become inflamed, than an increased secretion of fuid takes place from their surface. 
Reasoning from analogy, is it not much atse probable, nay, almost certain, that in tis tirst stage of pneumonia, the air cells axe in s preternaturally dry state, dependent gipn suppression of secretion? If this be tite condition of the membrane, it is obvious tist the crepitous rattle does not depend apon the presence of a mucous or sanguinevus fuid and air, which is generally supFosed to be its cause. I am of opinion, that Lit crepitous rattle attends a preternatural degree of dryness of the lining of the air. cels; that it depends upon the friction of air arainst the internal surfaces of the air. cells, and upon the friction of opposite sur. fares of the air-cells against each other, occming during respiration. A sound similar to the pulmonary crejitous rattle, may be prodaced in the commencement of inflammattun of synovial membranes, by gentle frition of opposite surfaces of the membrane gaginst each other. In emphysema of the lunas, a crepitous rattle of a similar charactir to that of pneumonia is heard, which cannot be supprosed to depend upon the prestice of any other fluid than air. All these circanstances appear to support strongly the truth of iny explanation; yet I must confess its with tiftidence I offer to the profession an esplanation of the cause of the phenome10n, not only different to that given by the irmortal Laennec, but different to that which thas, I helieve, been genérally recerved by wis iollowers. If my opinions are erroneous, in will be most satisfactory to me to have them confuted.

The sonorous rattle, it is probable, de. pends upon the passag cof air throngh a brostial tuhe deprived of its natural defrect of humidity.

The sound described as resembling the weding of new leather, is explicable by the codition of the membrane inflamed. It is lard at the commencement of pericarditis, at which tine we may suppose, that the scetion from the membrane is suppressed; and that friction of opposite surfaces of the is ataned pericardium produce this peculiar

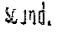

Ior. 14, 1829.

YEDDLESOME MIDWIFERY.

\section{To the Editor of The LanceT.}

$s_{\mathrm{s}},-\mathrm{I}$ trust you will permit the inserati cithe following remarks upon a commu2.4.13n in your Number for October 31st, *...: "Cases Demonstrative of the Eff. $\therefore$ aille tirgot of Rye."

ine atticle in question certainly proves - 4 Exacy of the secale, but it furnishes * atily instances of rass, offeious, and

$\because j, j, 0.0$ unnecessary interference with the parturient process. The exceedingly beautiful process of parturition is either not understood by Mr. Girtin, or, if understood, is lost sight of at a moment when it would be well to have it in mind. According to his own showing, the administration of the se. cale was unnecessary in the nine recited cases.

He seems unmindful of the benefit derived from the first stage of labour, and appears to view any other pains than " propulsive" as unnecessary. The partial sub. sidence, or total suspension of pains for a short time, seems to furnish a proper case for the ergot. The sharp lancinating pains are useless. The danger of hurrying the fœtal head through an unprepared pelvis and an unyielding perineum, is forgotten.

I will briefly allude to each case, and ap. peal to the experienced accoucheur whe. ther I am correct.

Case I.- "After four hours" pain, the pains subsided;" surely there is nothing very unusual in that-nothing that justified the ergot (except the accoucheur's anxiety to be gone). If the subsidence of pain be a good reason for giving ergot, it would be well to give a dose immediately on entering the lying-in-room, for the sound of the acconcheur's footsteps has generally the effect. of putting a stop to the uterine action for a time.

Case II.-In this case, "the pains steadily improved from eight till ten o'clock, when they slackened, and were feeble and ineffective for three hours-in all, eight hours from the commencement. The ergot was given." Why, I cannot divine.

Case III.-Hæmorrhage to a great ex. tent-no mention made of its cause. $\mathrm{He}$ must be a very bold, or a very timid prac. titioner, who dare trust to any medicine, where " a chamber-pot was filled with b'ood in an instant, and the bleeding continued in a mitigated stream till my arrival." It is right I should add, that "cold applications to the rulva had some effect."

Case IV.- In this case labour could scarcely be said to have commenced-that possible danger was to be apprehended from waiting? A few drops of liq. op. sedativ. would have put a stop to the inefficient pains.

Case V._" The pains were sharp and lancinating, with much abdominal uneasiness ;" in other words, they were dilating. pains ; that these pains are part of the simple parturient process, never seems to have struck your communicant. The ergot here was uncalled for.

* Drs. Burns and Hamilton allow twelve bours for the first stage. 